1. B. Pharm, M. Pharm, PhD Assistant Professor Pharmaceutical Chemistry

Ziaudding University Karachi.

2. Pharm D, M.Phil

Lecturer Pharmacy Practice

Ziauddin University Karachi.

3. B.Pharm, M.Phil, PhD

Assistant Professor Pharmaceutical Sciences

Dow University Karachi.

4. B.Pharm, Ph.D

Associate Professor Pharmaceutical Chemistry

Jinnah University for Women Karachi.

5. B.Pharm, M.Phil, Ph.D

Associate Professor Pharmaceutics

Ziauddin University Karachi.

6. Pharm.D

University of Sindh, Jamshoro.

7. B.Pharm, M.Pharm

Pharmaceutics

University of Karachi.

Correspondence Address:

Dr. Saira Shahnaz

Department of Pharmacy Practice

Ziauddin University Karachi.

sara61413@gmail.com

Article received on:

29/07/2019

Accepted for publication

03/10/2020

\section{Evaluation of common withdrawal effects; A surveillance study among drugs abusers at Rehabilitation Centers of Karachi.}

\author{
Quratulain Leghari ${ }^{1}$, Saira Shahnaz ${ }^{2}$, Rabiya Munawar ${ }^{3}$, Somia Gul ${ }^{4}$, Syed Imran $\mathrm{Ali}^{5}$, \\ Syed Wajid Ali Shah ${ }^{6}$, Sharmeen Bawani ${ }^{7}$
}

ABSTRACT... Objective: This study was to assess the common withdrawal effects of drugs among addicted population in rehabilitation. Study Design: Cross Sectional Survey. Setting: Different Rehabilitation Centers Located Across the City, Karachi. Period: December 2018 to June 2019. Material \& Methods: 400 filled questionnaires were obtained from randomly selected subjects (addicted persons). Results: The results of the study showed, most drugs abused age group is $20-40$ year i.e. $71.6 \%, 13-19$ year $18.7 \%$, and $9.7 \%$ for population above 40 years of age. Most abused drugs found 34.8\%, 26.8\%, 9.6\% 6.7\% for cannabis, tobacco, heroin, and morphine accordingly. $n=188(47 \%)$ of patients had adaptive response towards treatment in rehabilitation while $n=60$ (15\%) shows negative and aggressive behaviors. $n=60(15 \%)$ patients found guilty of drugs abused while $n=18045 \%$ found it pleasurable. Conclusions: A persistent, safe and evidence-based practices is required in management of drugs abuse among the addicted patients to avoid the risk factors.

Key words: $\quad$ Abuse, Drugs, Misuse, Narcotics, Rehabilitation.

Article Citation: Leghari Q, Shahnaz S, Munawar R, Gul S, Ali SI, Shah SWA, Bawani S. Evaluation of common withdrawal effects; a surveillance study among drugs abusers at Rehabilitation Centers of Karachi. Professional Med J 2021; 28(1):27-31. https://doi.org/10.29309/TPMJ/2021.28.01.3981

\section{INTRODUCTION}

In spite the general reductions in the drugs abuse cases, the prevalence rate of non-medical use of drugs remains the serious public health concern. ${ }^{1}$ In year 2009, peoples of aged 12 years, 5.3 million reported nonmedical use of pain relievers, which was found to be one-third of dependency and abuse cases according to US national survey on drugs use and Health. The highest prevalence of such case was found between the age group of 12-17 years and reported difference in the nonmedical use of drugs from year 2013 to 2014 was observed to be increased by $6 \%$, as 41.6 million people was reported in 2013 and 44.2 million in year $2014 .^{2}$ Due to the lack of quantitative surveillance, reporting and difficulty in the detection of such cases made these scenarios more dramatic. ${ }^{3}$ Drugs abuse has become more popular in the developing countries, and situation is worse for the countries like Pakistan. ${ }^{4}$ The commonly abused drugs are cannabis, tobacco, some potent analgesics like morphine, codeine, meperidine and fentanyl. ${ }^{5}$ Because of the intense response produced by the interaction of several opiates and the brain, these drugs remain extremely addictive, sometimes causing measurable symptoms of addiction in under three days. ${ }^{6}$ the narcotics abuse remains as leading crisis in health care setup, which includes several side effects for persistent users with/without prescription. ${ }^{7}$ Drug addiction has become one of the social problems all over the world. ${ }^{8}$ Every community is trying hard to resolve this issue, but its success rate is very low. Drug addicts are rejected group of the society that require special care and attention. If these people do not get proper care and treatment, it may cause harm to themselves as well as cause damage to the family and society. The drug rehabilitation centers assist drug addicts' people to prepare themselves to reenter to their society. In drug rehab, drug addicts do their best to restore their normal lifestyle in a safe and healthy way. ${ }^{9-10}$ The main objective of the study was to assess the patient's response towards withdrawal symptoms and their treatment at rehabilitation. 


\section{MATERIAL \& METHODS}

A cross sectional survey was conducted from December 2018 to June 2019. Total 400 filled questionnaires were obtained from randomly selected subjects (addicted persons) from different rehabilitation centers located across the city, Karachi. Questionnaire designed was based on the withdrawal symptoms, effects and treatment protocols and modified as Pakistani settings of rehabilitation center. The questionnaire was containing complete demographics of the respondents. It was distributed into two parts, one specified for physician and one for patients. The questions were framed to evaluate the knowledge about withdrawal effects of abused drugs and their treatment by rehabilitation center. Nawab House, Karachi Psychiatric Hospital, Civil Hospital Karachi, IBTADA.

\section{RESULTS}

The questionnaires were distributed to physicians and patients, 400 questionnaires were filled by physicians from different allocated rehabilitation centers, 400 questionnaires were filled after indepth interview from addicted patients. All the questionnaires were satisfactorily responded by patients making the response rate $100 \%$.

Table-I Most of the adult age group of people was prone towards drug addiction, due to many reasons including; less attention of elders on their children, social circle, depression, sex desires, and emotional issues.

\begin{tabular}{|l|c|c|}
\hline \multicolumn{1}{|c|}{ Age Groups } & $\begin{array}{c}\text { Respondents } \\
\text { Frequency }\end{array}$ & Percentage \\
\hline 6-12 years & Nil & $0 \%$ \\
\hline 13-19 years & 75 & $18.7 \%$ \\
\hline 20-40 years & 286 & $71.6 \%$ \\
\hline 40 years \& above & 39 & $9.7 \%$ \\
\hline
\end{tabular}

The most abused drug in Pakistan is cannabis being abuse by $n=139$ (34.8\%) of the abusive population, while the second major drug is heroin $n=38(9.6 \%)$ and cocaine $n=83(20.5 \%)$, other drugs includes; morphine $n=27(6.7 \%)$, tobacco $\mathrm{n}=107(26.8 \%)$ other unspecified drugs include alcoholic drinks, found $n=6(1.6 \%)$.

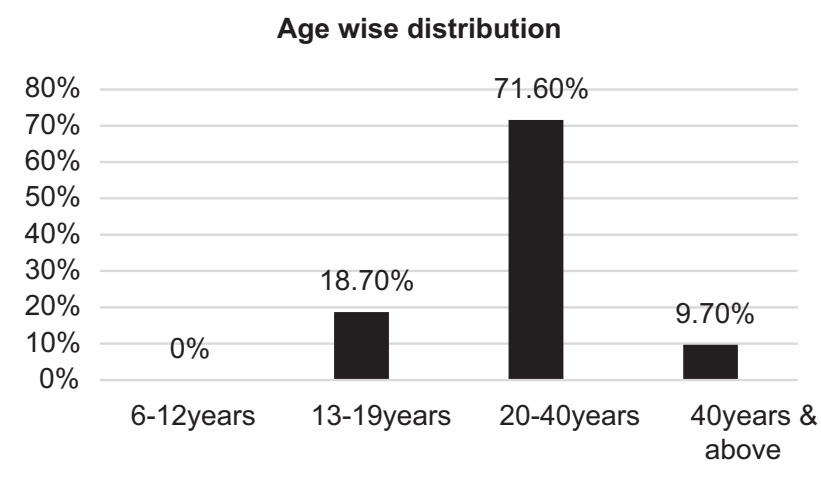

Figure-1

Mostly abused drugs

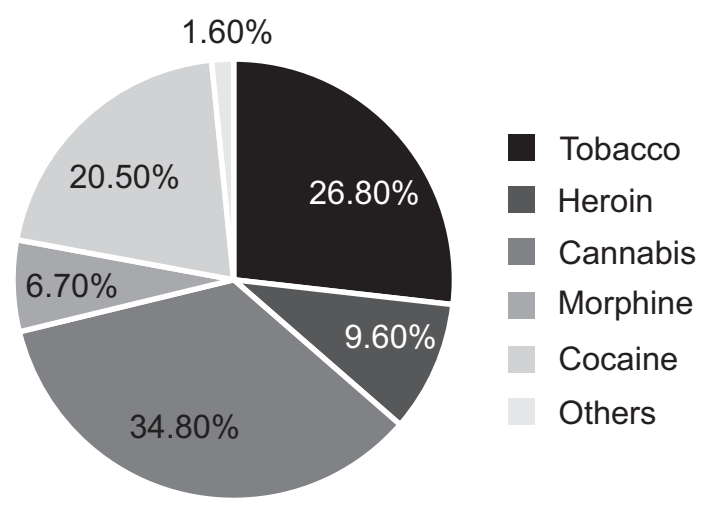

According to the Physician response the best treatment protocol during rehabilitation is pharmacological therapy, due to its readily responsiveness and concordance. Now other protocols are also being introduced to increase patient compliance and wellness towards detox therapy.

\begin{tabular}{|c|c|c|c|c|}
\hline $\begin{array}{c}\text { Counseling } \\
\text { Sessions }\end{array}$ & $\begin{array}{c}\text { Physical } \\
\text { Activities }\end{array}$ & $\begin{array}{c}\text { Pharma- } \\
\text { cological } \\
\text { Therapy }\end{array}$ & $\begin{array}{c}\text { Diet Plan } \\
\text { Changes }\end{array}$ & $\begin{array}{c}\text { Admitting } \\
\text { to } \\
\text { Psychiatric } \\
\text { unit. }\end{array}$ \\
\hline $20 \%$ & $5 \%$ & $50 \%$ & $5 \%$ & $20 \%$ \\
\hline
\end{tabular}

The common withdrawal symptoms that experienced by abuser on stopping supply of narcotics. Mainly narcotics are affecting on the brain, so they tend to induce brain disorders mostly i.e. $40 \%$, secondly, Gl disturbances $30 \%$ are also seen in withdrawal effects. Others include respiratory $20 \%$ and muscular dysfunction and muscles twitching $10 \%$ found as common effects. 


\begin{tabular}{|c|c|c|c|}
\hline \multicolumn{4}{|c|}{ Duration of narcotics abuse: } \\
\hline 6 months & 1 year & 5 years & Above 10 yrs. \\
\hline $68(17 \%)$ & $60(15 \%)$ & $112(28 \%)$ & $160(40 \%)$ \\
\hline \multicolumn{4}{|c|}{ Patients response to treatment: } \\
\hline Assertive & Interrogative & Aggressive / Negative & Adaptive \\
\hline $80(20 \%)$ & $72(18 \%)$ & $60(15 \%)$ & $188(47 \%)$ \\
\hline \multicolumn{4}{|c|}{ Effect on brain efficiency while using narcotics: } \\
\hline Strongly Agreed & Agree & Moderate & Disagree \\
\hline $68(17 \%)$ & $192(48 \%)$ & $128(32 \%)$ & $12(3 \%)$ \\
\hline \multicolumn{4}{|c|}{ Common feelings after taking narcotics: } \\
\hline Pleasurable & Irritable & Guilty/ Depressed & Sedative \\
\hline $180(45 \%)$ & $48(12 \%)$ & $60(15 \%)$ & $112(28 \%)$ \\
\hline \multicolumn{4}{|c|}{ Experience at rehabilitation: } \\
\hline Good & Better & Fair & Bad \\
\hline $172(43 \%)$ & $96(24 \%)$ & $28(7 \%)$ & $104(26 \%)$ \\
\hline Beginning & After Advice & symptoms/effects & Embarrassment \\
\hline $96(24 \%)$ & 80 (20\%) & $164(41 \%)$ & 60 (15\%) \\
\hline
\end{tabular}

Most of the patient shows adaptive response i.e. $n=188(47 \%)$ since they came here in rehabilitation after proper emotional family training. So that's why they are fully prepared to get rid of this curse. While aggressive and negative response was observed from $n=60$ (15\%) patients, $n=72$ (18\%) patients showed interrogative response to the given treatment, and equally $15 \%(n=9)$ patients followed asserted behavior to the therapy. Most of the drugs abusers had experience of drug abusing more than 5 years i.e. $n=112(28 \%)$, 10 years $n=160(40 \%), n=60(15 \%)$ abused for 1 year, and $n=68$ (17\%) was responded for 6 months of abuse. According to the abusers, the most common feelings and emotions after taking drugs are usually pleasurable and sedative due to their effect on brain receptor.

This is the main effect and as well as withdrawal effect of narcotics on brain efficiency, these drugs attach on opioid receptors and make a reason of brain disorders. Some abusers having strong perception regarding their brain deficiency while some having no idea that either it effects on brain or not.

Most of the patients have good experience in the rehabilitation center, while some have better and fair experience while very less patients have bad or worst experience at rehabilitation center.

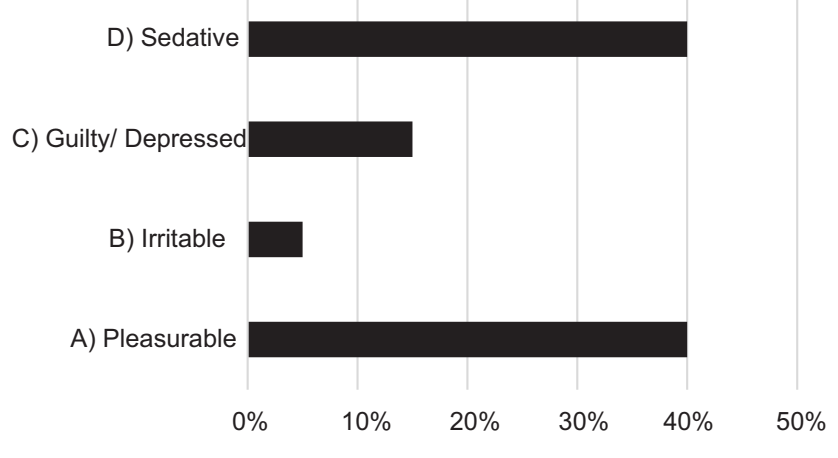

DISCUSSION

This study found that physicians have some mixed beliefs about the narcotics abuse regarding age group, some accurate belief and some inaccurate belief like our study. ${ }^{11}$ The physician sampled in this study were accurate in their agreement about the narcotics abuse of age from 20-40 years, because of a lot of reasons that is due to their bad company, isolation, pleasure sleekness and depression. The drugs related overuse was found with cocaine and heroin in most cases as found in the similar study conducted ${ }^{12}$ Drug abuse is continuing to present a significant public health problem. However, In Pakistan the most abused drug is cannabis/marijuana (charas). Most of the population is abusing due to its easy availability on specific areas by "dealers or agents" who are just on a phone call away, generally hidden from the preying eyes of enforcement agencies, 
however severe long term cognitive effects are inadequately studied adverse effects of cannabis which is worsening the situation of drug addicted persons ${ }^{13}$ The secondly most abused drugs are heroin and cocaine so called as street drugs are majorly being abused by below the age of 30 , as results showed in a similar study, most drugs abused and non-medical use (35\%) of drugs was found with age group of $18-25$ years ${ }^{14}$ Drug treatment mainly engage to help addicted patients to stop compulsive drug addiction and use. Drugs abuse and even withdrawal symptoms effects the CNS and patients experience the symptoms of loss of memory and sometimes aggressions, to this context Patients were asked about the effects of drugs on brain and $50 \%$ were found agreed with the effectiveness on abused drugs on brain efficiency similar results were observed in a study. ${ }^{15-16}$ Treatment can be given in a variety of procedures, take many different forms, and last for different periods of time in rehabilitation centers. ${ }^{17}$ The most common withdrawal observed are CNS effects which are mainly bipolar mood disorder, manic depression, and headache as reported in a study ${ }^{18}$ due to highly effects of misused drugs, and nonprescription use of narcotics analgesics on brain as a similar study found the cognitive impairments among drugs addicted person. ${ }^{19}$ Response to the rehabilitation treatment is found different with respect to patients ${ }^{20}$ as reported study suggested around the globe. Other risk factor found responsible were older age, chronic pain and misguidance. ${ }^{21-22}$ In achieving the optimal response in rehabilitation sequences in treatment suggested.

\section{LIMITATION OF STUDY}

This research can be conducted to larger population, due to improper patient's response only small sample size was considered.

\section{CONCLUSION}

There are several schemes formulated for treatment of drug addiction because addicted person's willingness towards drug addiction requires intense and sustained attention by well trained staff and equipped services.

Copyright@ 03 Oct, 2020.

\section{REFERENCES}

1. J. David Hawkins, Richard E Catalano, and Janet $Y$ Miller risk and protective factors for alcohol and other drug problems in adolescence and early adulthood: Implications for substance abuse prevention. Psychological Bulletin 1992, Vol. 112. No. 1.64-105.

2. Bluth $\mathrm{MH}$, Pincus MR. Narcotic analgesics and common drugs of abuse: Clinical correlations and laboratory assessment. Clinics in Laboratory Medicine. 2016 Dec 1;36(4):603-34.

3. United States Food and Drug Administration (FDA). 5600 Fishers Lane, Rockville, MD 20857-0001.

4. New drugs of abuse, Pharmacotherapy Volume 35, Number 2, 2015 pages 190-197.

5. Christoph Stein, The opiods receptors, Annual review of medicine, volume 67, 2016. Stein, Pages 433-451.

6. Gowing, L., Ali, R., \& White, J. M. (2017). Opioid antagonists with minimal sedation for opioid withdrawal. Cochrane Database of Systematic Reviews. Cochrane Database of Systematic Reviews 2017, Issue 5. Pages 1-53.

7. Qureshi R, Puvanesarajah V, Werner BC, Jain A, Menga EN, Shen FH, Hassanzadeh $\mathrm{H}$. Risk factors for narcotic use beyond three months after lumbar spinal deformity surgery. The Spine Journal. 2017 Oct $1 ; 17(10):$ S259.

8. National Institute on Drug Abuse (NIDA). 6001 Executive Boulevard, Room 5213, Bethesda, MD 208929561.

9. Rehman, Ziaur, Suzan Khoromi, and James E. Douglas. "Opioid Abuse". eMedicine, August 15, 2004. Available online at http://www.emedicine.com/med/topic/ topic1673.htm (accessed November 30,2004).

10. Peltz G, Clark D, Lawrence $\mathrm{CH}$, inventors; Leland Stanford Junior University, assignee. Methods and compositions for treating or preventing narcotic withdrawal symptoms. United States patent US 9,226,918. 2016 Jan 5.

11. Abebe W. Herbal medication: potential for adverse interactions with analgesic drugs. Journal of clinical pharmacy and therapeutics. 2002 Dec;27(6):391-401.

12. Paulozzi LJ, Budnitz DS, Xi Y. Increasing deaths from opioid analgesicsin the United States. Pharmacoepidemiol Drug Saf. 2006; 15(9): 618-627. 
13. Pope Jr HG, Gruber AJ, Yurgelun-Todd D. The residual neuropsychological effects of cannabis: the current status of research. Drug and alcohol dependence. 1995 Apr 1;38(1):25-34.

14. Substance abuse and mental health services administration. Results from the 2009 National Survey on Drug Use and Health: Volume I. Summary of National Findings (Office of Applied Studies, NSDUH Series H-38A, HHS Publication No. SMA 10-4856). Rockville, MD. Available at: http://oas.samhsa.gov/ NSDUH/2k9NSDUH/2k9Results.htm\#Ch2. Accessed July 23, 2011.

15. Rehman, Ziaur, Suzan Khoromi, and James E. Douglas. "Opioid Abuse". eMedicine, August 15, 2004.

16. Pope HG, Gruber AJ, Hudson JI, Huestis MA, YurgelunTodd D. Neuropsychological performance in longterm cannabis users. Archives of general psychiatry. 2001 Oct 1;58(10):909-15.

17. Wall M, Cheslack-Postava K, Hu MC, Feng T, Griesler $P$, Kandel DB. Nonmedical prescription opioids and pathways of drug involvement in the US: Generational differences. Drug and alcohol dependence. 2018 Jan 1;182:103-11.
18. Robert J. Thoma Mollie A. Monnig Per A. Lysne David A. Ruhl Jessica A. Pommy Michael Bogenschutz J. Scott Tonigan Ronald A. Yeo Adolescent substance abuse: The effects of alcohol and marijuana on neuropsychological performance alcohol Clin Exp Res, Vol 35, No 1, 2011:39-46. DOI: 10.1111/j.15300277.2010.01320.x

19. Rehman, Ziaur, Suzan Khoromi, and James E. Douglas. "Opioid Abuse". eMedicine, August 15, 2004. Available online at http://www.emedicine.com/med/topic/ topic1673.htm (accessed November 30,2004).

20. American academy of child and adolescent psychiatry. 3615 Wisconsin Avenue, NW, Washinton, GC 20016-3007.

21. Harbaugh CM, Lee JS, Hu HM, McCabe SE, VoepelLewis T, Englesbe MJ, Brummett CM, Waljee JF. Persistent opioid use among pediatric patients after surgery. Pediatrics. 2018 Jan 1;141(1).

22. Maremmani I, Gerra G, Ripamonti IC, Mugelli A, Allegri M, Viganò R, Romualdi P, Pinto C, Raffaeli W, COLUZZI10 F, GATTI11 RC. The prevention of analgesic opioids abuse: expert opinion. Eur Rev Med Pharmacol Sci. 2015 Nov 1;19(21):4203-6.

\begin{tabular}{|c|c|c|c|}
\hline \multicolumn{4}{|c|}{ AUTHORSHIP AND CONTRIBUTION DECLARATION } \\
\hline Sr. \# & Author(s) Full Name & Contribution to the paper & Author(s) Signature \\
\hline 1 & Quratulain Leghari & Concept & \\
\hline 2 & Saira Shahnaz & Write up / Analysis. & \\
\hline 3 & Rabiya Munawar & Analysis. & \\
\hline 4 & Somia Gul & Data analysis. & \\
\hline 5 & Syed Imran Ali & Proof reading. & \\
\hline 6 & Syed Wajid Ali Shah & Proof reading. & \\
\hline 7 & Sharmeen Bawani & Data collection. & \\
\hline
\end{tabular}

